\title{
Rapid and sensitive LC-MS/MS method for the determination of auraptene in rat plasma and its application in a pharmacokinetic and bioavailability study in rats
}

X.D. Ye ${ }^{1 *}$, H. Ouyang $1,2 *$, L.Y. Zhong ${ }^{1}$ T.E. Li ${ }^{1}$ X.Y. Rao ${ }^{1}$, Y.L. Feng ${ }^{2}$ and W.L. Yang ${ }^{1}$

${ }^{1}$ Jiangxi University of Traditional Chinese Medicine, Nanchang, China ${ }^{2}$ State Key Laboratory of Innovative Drug and Efficient Energy-Saving Pharmaceutical Equipment, Nanchang, China

*These authors contributed equally to this study. Corresponding authors: Y.L. Feng / W.L. Yang

E-mail: fengyulin2003@126.com / yangwuliang@163.com

Genet. Mol. Res. 15 (2): gmr.15028786

Received May 16, 2016

Accepted June 3, 2016

Published June 24, 2016

DOI http://dx.doi.org/10.4238/gmr.15028786

\begin{abstract}
A simple, sensitive and specific liquid chromatographytandem mass spectrometry method was developed and validated for the determination of auraptene, a constituent isolated from Fructus aurantii with potential to combat Alzheimer's disease, in rat plasma. Rat plasma samples were pretreated by protein precipitation with methanol. The analytes were separated by a Waters Sun Fire C18 column $(50 \mathrm{~mm}$ x $2 \mathrm{~mm}, 5 \mu \mathrm{m}$ ) and eluted with 1:1000 methanol and formic acid/water (v/v) mobile phase with a flow rate of $0.5 \mathrm{~mL} / \mathrm{min}$. Multiple reaction monitoring was used to monitor the transition of the deprotonated auraptene molecule with an $\mathrm{m} / \mathrm{z}$ of $299.3[\mathrm{M}+\mathrm{H}]^{+}$, to the product ion with an $\mathrm{m} / \mathrm{z}$ of $162.9[\mathrm{M}+\mathrm{H}]^{+}$. Progesterone, with an $\mathrm{m} / \mathrm{z}$ of $315.2 \rightarrow$ 96.9 was used as an internal standard. The limits of detection and of quantification of auraptene in the rat plasma were 1 and $5 \mathrm{ng} / \mathrm{mL}$,
\end{abstract}


respectively. The method was linear in the concentration range of 20$2000 \mathrm{ng} / \mathrm{mL}$ with coefficient correlation of 0.9956 . After auraptene (100 mg/kg, p.o.) administration, the maximum plasma concentration and the time taken to reach maximum concentration were $1719.5 \pm$ $384.3 \mathrm{~g} / \mathrm{mL}$ and $108.0 \pm 25.3 \mathrm{~min}$, respectively. The elimination halflife was $108.0 \pm 25.3$ for auraptene $(100 \mathrm{mg} / \mathrm{kg}$, p.o. $)$ and $3.0 \pm 0 \mathrm{~min}$ for auraptene $(2 \mathrm{mg} / \mathrm{kg}, i . v$.). The oral bioavailability was about $8.5 \%$.

Key words: Auraptene; LC-MS/MS; Pharmacokinetics; Bioavailability; Rat

\section{INTRODUCTION}

Auraptene, a kind of coumarin compound, is mainly isolated and purified from Fructus aurantii (Yang et al., 2008). Auraptene is a compound with a wide spectrum of pharmacological activities such as anti-inflammatory (Tanaka et al., 1999), antioxidant, and antitumoral activities (Kawabata et al., 2006). Recent studies demonstrate that auraptene shows a new biological action, namely improving learning and memory ability in animals (Zhang et al., 2011; Chen et al., 2012; Ye et al., 2012; Chen et al., 2014) and hint at a wide scope for safe drug use for related purposes.

In view of the clinical potential of auraptene, it is imperative to investigate its pharmacokinetics and bioavailability for further research. Therefore, it is necessary to develop a reliable bioanalytical method for the analysis of auraptene in biological samples. Very few analytical methods have been developed to quantify auraptene in biological samples. In the course of our literature investigation, a few studies on the pharmacokinetics of auraptene using high-performance liquid chromatography (HPLC) with UV detection have been reported (Yuan et al., 2011; Yuan et al., 2012). However, they are difficult to adapt to concentration monitoring in vivo. To the best of our knowledge, no validated LC-MS/MS method has been reported in the literature for the quantification of auraptene in rat plasma. The liquid chromatography-tandem mass spectrometry (LC-MS) technique combines the efficient separation capability of LC and high sensitivity and structural characterization abilities of MS, and has been widely applied in identifying and quantifying natural compounds in plants or biological fluids (Guo et al., 2014).

Therefore, a reliable and rapid LC-MS/MS method for the quantification of auraptene was developed in this study. The method validation was performed as per the US Food and Drug Administration guidelines and the results met the acceptance criteria. The method was then applied to assess the pharmacokinetics and oral bioavailability of auraptene.

\section{MATERIAL AND METHODS}

\section{Chemical, reagents, and materials}

Auraptene with $98 \%$ purity was extracted from Citrus aurantium L. by our laboratory. Chemical structure of auraptene is shown in Figure 1. HPLC-grade methanol, acetonitrile and formic acid were purchased from Fisher Scientific (USA). Deionized water was produced with Element A10 equipment (Millipore, Bedford, MA, USA). Heparin sodium injection I.P. (1000 $\mathrm{IU} / \mathrm{mL}$ ) was supplied by Qianhong Biochemical Pharma Pvt. Limited (Changzhou, China). 
Progesterone used as an internal standard (IS) was obtained from the National Institute for Control of Pharmaceutical and Biological Products (Beijing, China) and its chemical structure is presented in Figure 1. All other chemical reagents were of analytical grade.

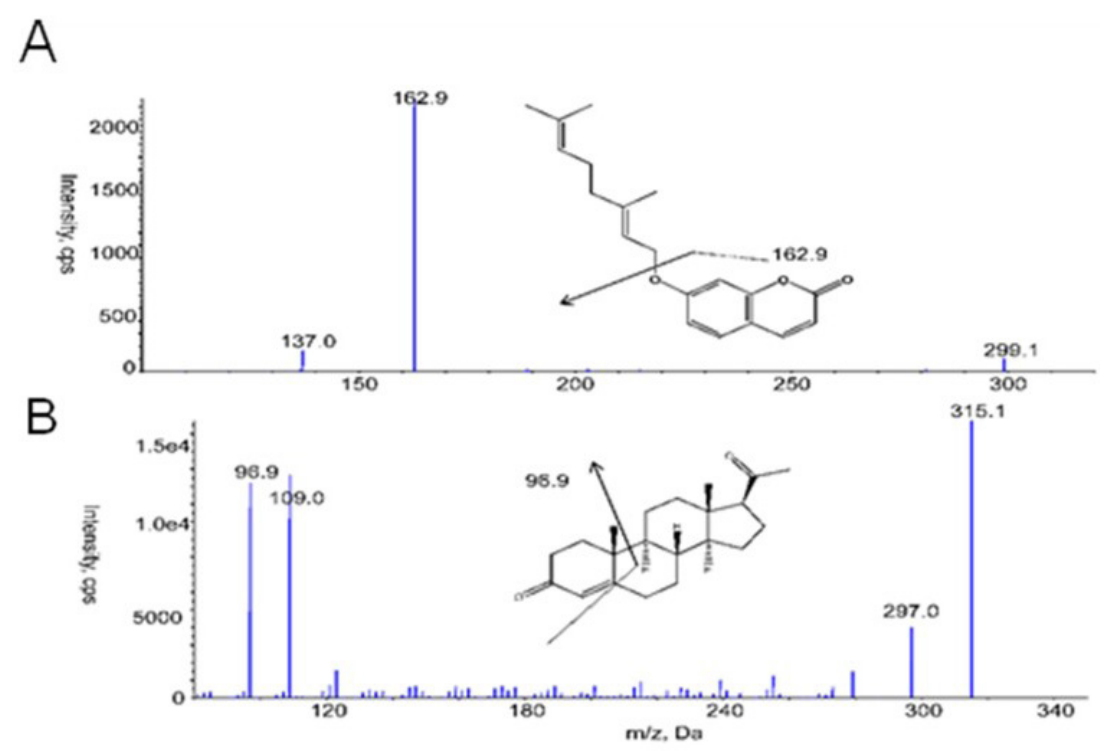

Figure 1. Chemical structures and product ion mass spectra of auraptene (A) and progesterone (B).

\section{Chromatographic conditions}

The analysis of all standards and samples in the study were performed on an HPLC system from Shimadzu (Kyoto, Japan) equipped with an SIL-30AC Auto Sampler, a LC30AD Solvent Delivery, a CTO-30AC Column Oven, a DGU-20A 3 Solvent Degasser, and a CBM-20A Controller. The chromatographic separation was carried out on Waters Sun Fire C18 column (50 mm x $2 \mathrm{~mm}, 5 \mathrm{~mm}$ ) (Milford, CT, USA). The overall mobile phase was composed of mobile phase A (MA) with 1:1000 formic acid/water (v/v) and mobile phase B (MB) with methanol. The system was run in the linear gradient elution program: 10\% MB (0-0.8 $\mathrm{min}$ ), from $10-90 \% \mathrm{MB}(0.8-1.2 \mathrm{~min}), 90 \% \mathrm{MB}$ (1.2-3.6 min), from $90-10 \% \mathrm{MB}$ (3.6$4.2 \mathrm{~min}$ ), and $10 \% \mathrm{MB}(4.2-5.0 \mathrm{~min})$ at a flow rate of $0.5 \mathrm{~mL} / \mathrm{min}$ and the run time for each injection was $5 \mathrm{~min}$. The injection volume was $5 \mu \mathrm{L}$ and the column oven temperature was maintained at $40^{\circ} \mathrm{C}$.

\section{Mass spectrometric conditions}

The MS analysis - that used a spectrometer equipped with Turbo V sources and Turbo ionspray $^{\mathrm{TM}}$ interface - was performed on a 4500 QTRAP $^{\mathrm{TM}}$ system obtained from Applied Biosystems (MDS-Sciex, Concord, Canada). Electrospray ionization was performed in the positive mode. The optimal MS spectrometric parameters produced were as follows: TIS temperature was $600^{\circ} \mathrm{C}$, ion spray (SI) voltage was $5500 \mathrm{~V}$, curtain gas (CUR), nitrogen was 30 , and nebulizing gas (GS1) and TIS gas (GS2) were set at the same value of 50 psi. The 
optimized declustering potentials (DP) for auraptene and IS were $120 \mathrm{~V}$ and $150 \mathrm{~V}$, respectively, and collision energy (CE) for auraptene and IS were the same value, $30 \mathrm{eV}$. Collision cell exit potential (CXP) was $15 \mathrm{~V}$. The precursor-product ion pair transitions as measured by multiple reaction monitoring $(\mathrm{MRM})$ mode were $\mathrm{m} / \mathrm{z}=299.3 \circledR 162.9$ for auraptene, and $\mathrm{m} / \mathrm{z}=315.2 \rightarrow$ 96.9 for IS, with a dwell time of $150 \mathrm{~ms}$ and $100 \mathrm{~ms}$, respectively. All acquired data were processed through Analyst Software ${ }^{\mathrm{TM}}$ (version 1.6.1).

\section{Preparation of stock and working solutions, calibration standards, and quality control samples}

Standard stock solutions of auraptene $(20.0 \mathrm{mg} / \mathrm{mL})$ and progesterone $(10.0 \mathrm{mg} /$ $\mathrm{mL}$ ) were prepared in methanol. Appropriate dilutions with of auraptene with methanol were made to produce working solutions of desired concentrations in order to prepare standards for calibration and quality control (QC). All concentrated solutions were stored at $-20^{\circ} \mathrm{C}$ until analysis.

Calibration standards of auraptene (20.0, 50.0, 100, 500, 1000, and $2000 \mathrm{ng} / \mathrm{mL})$ were prepared daily by adding the appropriate aliquots of stock and working solutions into blank rat plasma. Quality control (QC) samples were prepared through individually spiking control rat plasma at concentrations of 20.0 [lower quality control (LQC)], 50.0 [middle quality control (MQC)], 1000.0 [higher quality control (HQC)], and $1600.0 \mathrm{ng} / \mathrm{mL}$ [data quality control (DQC)] and aliquoted into $2.0-\mathrm{mL}$ centrifuge tubes. The samples were stored at $-40^{\circ} \mathrm{C}$ until analysis.

\section{Sample preparation}

Plasma samples were prepared by a simple and rapid protein precipitation method. The frozen plasma samples were removed from $-40^{\circ} \mathrm{C}$ storage and thawed at room temperature. To $50 \mu \mathrm{L}$ plasma samples, $300 \mu \mathrm{L}$ methanol was added and then mixed with $40 \mu \mathrm{L}$ IS solution at $10.0 \mu \mathrm{g} / \mathrm{mL}$ for $30 \mathrm{~s}$. Other samples including calibration standards, QC samples, incurred samples, and blank matrix controls were vortex-mixed thoroughly for $5 \mathrm{~min}$, followed by centrifugation for $10 \mathrm{~min}$ at $15,000 \mathrm{rpm}$ on H2100R (XiangYi, China). The prepared supernatants were moved to automatic sampler vials and injected into the LC-MS/MS system.

\section{Bioanalytical method validation}

The validated method for the assay in rat plasma was performed in accordance with USFDA draft guidelines.

\section{Specificity and selectivity}

The specificity of the method was assessed by analyzing the chromatograms from six different blank rat plasma samples to investigate the potential interferences at the retention time for the analytes and IS. The sensitivity of the method was determined by investigating the signal to noise ratio of lower limit of quantitation (LLOQ) samples. Carryover of the analyte was confirmed through estimating blank rat plasma extract samples behind the injection of an upper limit of quantification (ULOQ) sample. 


\section{Calibration curve}

The calibration curve of auraptene was achieved by plotting the peak area ratios of auraptene to IS versus the nominal concentration of the calibration standards. The ultimate calibration standard concentrations used for plotting the calibration curve were 20.0, 50.0, $100.0,500.0,1000.0$, and $2000.0 \mathrm{ng} / \mathrm{mL}$. Linearity was evaluated by weighted $\left(1 / \mathrm{x}^{2}\right)$ least squares regression analysis.

\section{Recovery and matrix effect}

The recovery of auraptene was determined by comparing the average peak areas of processed QC samples [20.0 (LQC), 50.0 (MQC), 1000.0 (HQC) ng/mL, and $1600.0 \mathrm{ng} / \mathrm{mL}$ (DQC)] with those of the corresponding standard solutions added to the blank plasma matrix, whereas those of IS were set at $1000 \mathrm{ng} / \mathrm{mL}$. The matrix effect was confirmed by comparing the peak areas of auraptene- and IS-spiked blank plasma samples analyzed by protein precipitation method with those of analytes in the neat solutions at the same concentrations. The established matrix effect was evaluated at 20.0 (LQC), 50.0 (MQC), 1000.0 (HQC) ng/mL, and $1600.0 \mathrm{ng} /$ $\mathrm{mL}$ (DQC). The matrix effect of IS was determined at $1000 \mathrm{ng} / \mathrm{mL}$.

\section{Precision and accuracy}

The accuracy and precision of intra-day and inter-day analyses were investigated by evaluating three different groups of rat plasma samples at two separate concentrations. Each group comprised the accepted calibration standards and five replicates at four different QC levels, i.e., 20.0, 50.0, 1000.0, and $1600.0 \mathrm{ng} / \mathrm{mL}$ (DQC). Dilution integrity was evaluated by a 10 -fold dilution of the DQC sample with blank plasma prior to extraction in one of the three batches. The criteria for acceptability of the data included accuracy within $\pm 15 \%$ relative error (RE) from the nominal values and a precision of within $\pm 15 \%$ relative standard deviation (RSD), whereas for LLOQ it cannot exceed $\pm 20 \%$ for either accuracy or precision measures.

\section{Stability experiments}

Stability studies were performed for the evaluation of analyte stability in stock solutions and in plasma samples at the two concentration levels, i.e., LQC and HQC sample concentrations, under various conditions using six replicates for each. The stability estimation at ambient temperature $\left(22^{\circ} \pm 2^{\circ} \mathrm{C}\right)$ was tested by analyzing samples stored for $24 \mathrm{~h}$. The longterm stability estimation was conducted by analyzing samples stored at $-40^{\circ} \pm 10^{\circ} \mathrm{C}$ for 60 days. Freeze/thaw stability was estimated for up to 5 cycles of freezing. The samples in each cycle were frozen for at least $12 \mathrm{~h}$ from $-40^{\circ}$ to $25^{\circ} \mathrm{C}$. Freezer stability of auraptene in rat plasma was evaluated by analyzing the QC samples stored at $-40^{\circ} \pm 10^{\circ} \mathrm{C}$ for 30 days. Post-preparative stability was evaluated by analyzing the treated samples placed in the automatic sampler for $48 \mathrm{~h}$. Samples were considered to be stable if assay values were within the acceptable limits of accuracy $( \pm 15 \% \mathrm{RE})$ and precision $(\leq 15 \% \mathrm{RSD})$.

\section{Pharmacokinetic study}

Sprague-Dawley male rats with Sprague-Dawley weight range of 200-260 g were 
supplied by the Laboratory Animal Center of Suzhou University (Suzhou, China). The rats were kept in controlled conditions $\left(20^{\circ}-22^{\circ} \mathrm{C}\right.$, relative humidity $55-70 \%, 12 \mathrm{~h}$ light-dark cycle) with free access to food and water for a week to acclimatize them to laboratory conditions prior to the experiments. The animal studies complied with the Guidelines for Animal Experimentation of Jiangxi University of Traditional Chinese Medicine (Jiangxi, China), required by the Institutional Animal Care and Use Committee (IACUC). The protocols for the animal experiments were approved by the IACUC.

The LC-MS/MS validated method was employed for the pharmacokinetic study of auraptene after oral administration at a dose of $100 \mathrm{mg} / \mathrm{kg}$ or intravenous injection at a dose of 2 $\mathrm{mg} / \mathrm{kg}$. Male rats in the study were randomly divided into two groups (6 rats in each group), one group for oral administration and the other for intravenous administration via the caudal vein. Blood samples $(0.2 \mathrm{~mL})$ were collected via retro-orbital puncture from the rats into microfuge tubes containing heparin anti-coagulant at $0,3,6,10,20,45,60,120,180,300,480,720$, and 1440 min post dose administration for both routes. Plasma was prepared by centrifuging the blood at 20,000 $\mathrm{g}$ for $5 \mathrm{~min}$ and then stored frozen at $-40^{\circ} \mathrm{C}$ until analysis. The acquired data and pharmacokinetic parameters were calculated using WinNonlin software standard version 6.1 (Pharsight Mountain View, Sunnyvale, CA, USA) based on the non-compartmental model. $\mathrm{C}_{\max }$ and $\mathrm{T}_{\max }$ were directly achieved from the observed concentration-versus-time data.

Data fitting and pharmacokinetic parameter calculations were carried out using the DAS 2.1.1 pharmacokinetic program (Chinese Pharmacology Society), in which the noncompartmental model was chosen. All results were expressed as arithmetic mean \pm standard deviation (S.D.). Bioavailability was calculated according to the following equation:

$$
\text { Bioavailabilty }(\mathrm{F} \%)=\frac{\mathrm{AUC}_{0 \rightarrow \infty}(\text { p.o. }) \times \operatorname{dose}(\text { i.v. })}{\mathrm{AUC}_{0 \rightarrow \infty}(\text { i.v. }) \times \operatorname{dose}(\text { p.o. })} \times 100 \text {. }
$$

\section{RESULTS AND DISCUSSION}

\section{Method development}

\section{LC-MS/MS conditions}

Several trials of column types and chromatographic conditions were conducted for developing a rapid, simple, and sensitive analytical method. A Waters SunFire 18 column $(50 \mathrm{~mm}$ x $2 \mathrm{~mm}, 5 \mu \mathrm{m}$ ) with a gradient mobile phase comprising methanol and water plus $0.1 \%$ formic acid at a flow rate of $0.5 \mathrm{~mL} / \mathrm{min}$ was chosen. These conditions offered the best compromise between selectivity, sensitivity, and speed of analysis and ameliorated peak shapes and high ion responses for both auraptene and progesterone (IS). The analysis time was only $5 \mathrm{~min}$.

Auraptene and progesterone (IS) showed higher sensitivity and stronger mass response with the electro spray ionization (ESI) operation in positive mode. The most abundant molecular ions for auraptene and IS are the corresponding $[\mathrm{M}+\mathrm{H}]^{+}$ions for auraptene $(\mathrm{m} / \mathrm{z}$ $299.3)$ and IS ( $\mathrm{m} / \mathrm{z}$ 315.2) respectively. The main fragment ion of auraptene was accelerated to an $\mathrm{m} / \mathrm{z}$ value of 162.9 under the MS2 condition and that of IS reached $\mathrm{m} / \mathrm{z} 96.9$ in similar way through optimizing distribution potential and collision energy (Figure 1). The ion pairs were chosen to possess m/z 299.3-162.9 for auraptene and $\mathrm{m} / \mathrm{z}$ 315.2-96.9 for IS because they exhibited strong mass response in multiple reaction monitoring (MRM) mode. 


\section{Internal standard}

The choice of an appropriate internal standard (IS) is indispensable for LC-MS/MS in order to perform an effective pharmacokinetic study. Progesterone, chloramphenicol, and reserpine were reviewed as internal standards. Progesterone was finally selected based on chromatographic elution, ionization response and extraction efficiency. Subsequent validated data achieved through the LC-MS/MS methodology using the chosen IS led us to feel certain of the analytical study.

\section{Method validation}

\section{Matrix effect and recovery}

From Table 1, the benchmark matrix effect values of auraptene were 90.4, 90.9, 89.5, and $91.1 \%$ with $20,50,1000$, and $1600 \mathrm{ng} / \mathrm{mL}$ levels, respectively. Matrix effect value of IS was $90.2 \%$ for a set concentration of $1000 \mathrm{ng} / \mathrm{mL}$. Besides, the values of IS-normalized MF were from 0.89 to 0.97 among the three assessed QC levels determined by appropriate evaluation and validated by the analytical method based on MF of IS. There was very little significant matrix effect based on the acquired data. The absolute extraction recovery values for auraptene in rat plasma were $90.4 \%(20 \mathrm{ng} / \mathrm{mL}), 90.9 \%(50 \mathrm{ng} / \mathrm{mL}), 89.5 \%(1000 \mathrm{ng} /$ $\mathrm{mL})$, and $91.1 \%(1600 \mathrm{ng} / \mathrm{mL})(\mathrm{N}=5)$ based on data from the repetition of four levels at each concentration, and that for IS was $90.2 \%(1000 \mathrm{ng} / \mathrm{mL}, \mathrm{N}=5)$. Collectively, the data suggested that the matrix effect and recovery rate quantiðcation for auraptene in rat plasma were applicable using this method.

Table 1. Extraction recovery and matrix effect of auraptene in rat plasma.

\begin{tabular}{l|c|c|c|c|c}
\hline Compounds & Nominal con. $(\mathrm{ng} / \mathrm{mL})$ & Recovery (\%) & RSD (\%) & IS normalized matrix & RSD (\%) \\
\hline Auraptene & 20 & 90.4 & 8.89 & 0.93 & 8.53 \\
\hline & 50 & 90.9 & 11.10 & 0.95 & 8.69 \\
\hline & 1000 & 89.5 & 2.16 & 0.89 & 2.72 \\
\hline & 1600 & 91.1 & 6.51 & 0.97 & 6.03 \\
\hline IS & 1000 & 90.2 & 6.04 & & \\
\hline
\end{tabular}

\section{Linearity, sensitivity, carryover, and specificity}

The calibration curve for auraptene showed good linearity over the concentration range of $20-2000 \mathrm{ng} / \mathrm{mL}$ in rat plasma with correlation coefficient $\left(\mathrm{R}^{2}\right)$ higher than 0.990 in all validated batches.

The linear regression equation for the calibration curve was $y=0.000518 x+0.000334$ $\left(\mathrm{R}^{2}=0.9956\right)$ during the course of validation.

The sensitivity was appraised by analyzing LLOQ at $20 \mathrm{ng} / \mathrm{mL}$ for auraptene in six replicates, in three validation batches.

The potential carry-over effect was trialed through immediate injection of blank plasma extract following ULOQ. In Figure 2, no significant interference was observed in the chromatographic region of blank plasma samples at the retention time of auraptene and IS at $30 \mathrm{~min}$ after oral administration of auraptene at a dosage of $100 \mathrm{mg} / \mathrm{kg}$.

The speciðcity of the method was evaluated by analyzing blank plasma of six different 
rats and comparing them with the corresponding plasma samples spiked with auraptene and IS for the exclusion of any endogenous co-eluting interferences.
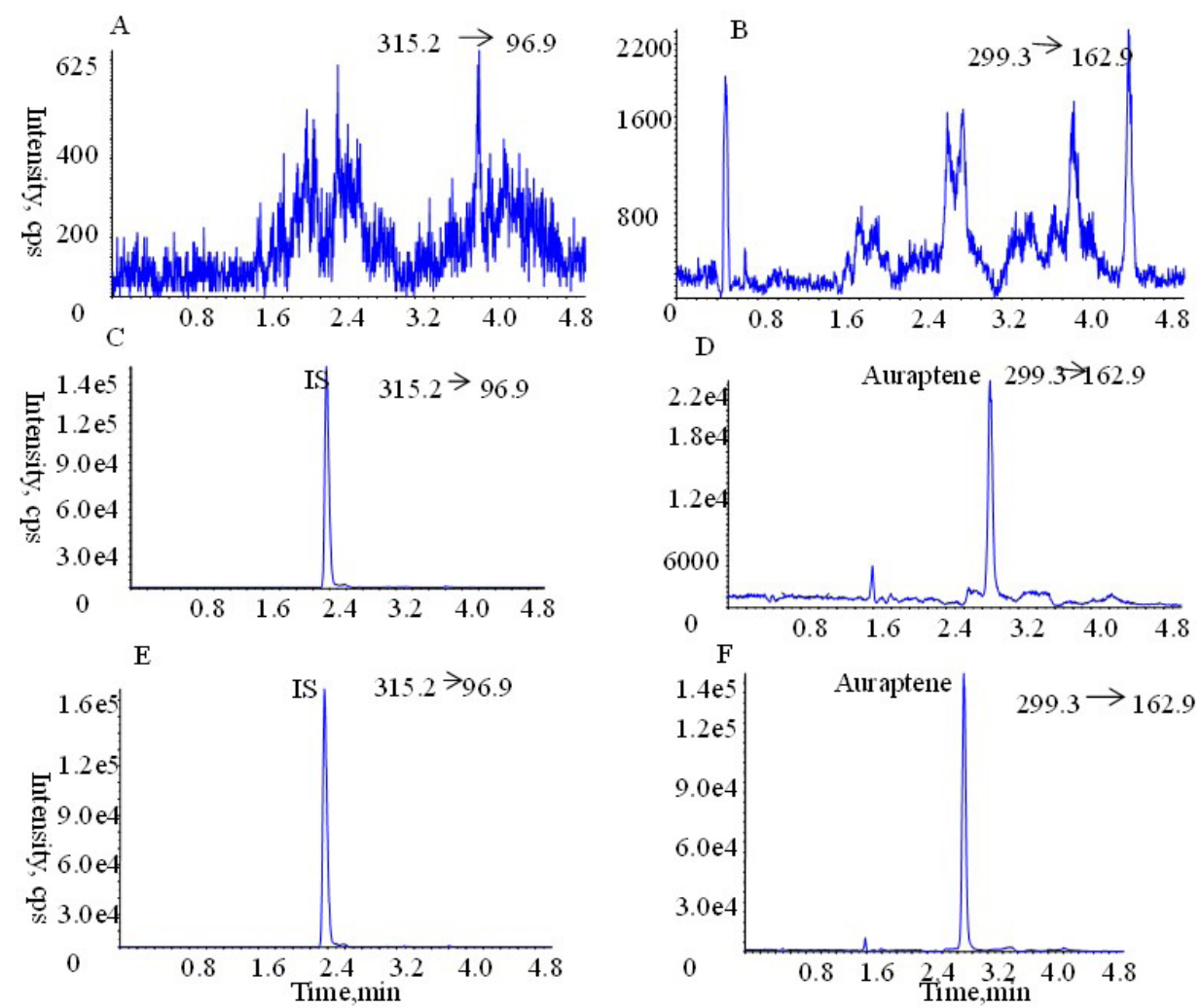

Figure 2. Representative multiple reaction monitoring chromatograms of auraptene and IS in rat plasma. A. and B. Blank plasma sample. C. and D. Blank plasma sample spiked with $2.00 \mathrm{ng} / \mathrm{mL}$ (LLOQ) of auraptene and 1000 $\mathrm{ng} / \mathrm{mL}$ of IS. E. and F. Plasma sample obtained $30 \mathrm{~min}$ after intragastric administration of auraptene at a dose of $100 \mathrm{mg} / \mathrm{kg}$.

\section{Precision and accuracy}

From Table 2, the precision and accuracy data for intra- and inter-day plasma sample auraptene levels were obtained by replication analysis $(\mathrm{N}=5)$ of four QC levels with 20,50, 1000 , and $1600 \mathrm{ng} / \mathrm{mL}$. The intra- and inter-day precision values RSD (\%) were lower than $15 \%$, and the accuracy values were within the range $93.1-102.0 \%$. The results suggested that the accuracy and precision of the validation method were satisfactory.

The precision and accuracy of the developed method were evaluated by analyzing ðve replicates of QC samples at three concentration levels in three batches. The precision was evaluated by the relative standard deviation (RSD, \%) and the accuracy was assessed by the ratio of determined concentration and corresponding actual concentration multiplied by $100 \%$. The accuracy at each concentration should be within $85-115 \%$ of the actual value, and the values for precision should not exceed $15 \%$. 
Table 2. Accuracy and precision for auraptene in rat plasma.

\begin{tabular}{|c|c|c|c|c|c|c|c|c|c|c|}
\hline \multirow[t]{3}{*}{ Statistical variables } & \multicolumn{10}{|c|}{ Theoretical concentration $(\mathrm{ng} / \mathrm{mL})$} \\
\hline & \multicolumn{5}{|c|}{ Intra-day $(\mathrm{N}=5)$} & \multicolumn{5}{|c|}{ Inter-day $(\mathrm{N}=5)$} \\
\hline & 20 & 50 & 1000 & 1600 & 16000 & 20 & 50 & 1000 & 1600 & 16000 \\
\hline Mean $(\mathrm{ng} / \mathrm{mL})$ & 19 & 48 & 1020 & 1582 & 15082 & 19 & 49 & 1006 & 1591 & 14904 \\
\hline RSD & 9.88 & 6.56 & 0.87 & 2.41 & 3.45 & 10.5 & 6.29 & 2.04 & 6.10 & 3.45 \\
\hline Accuracy (\%) & 98.0 & 97.0 & 102.0 & 98.9 & 94.3 & 96.0 & 98.0 & 100.6 & 99.4 & 93.1 \\
\hline
\end{tabular}

\section{Dilution integrity}

The dilution integrity of ULOQ for auraptene was extended to $16,000 \mathrm{ng} / \mathrm{mL}$ with a 10 times dilution for the prepared rat blank plasma. In Table 2, the percentage mean of both precision and accuracy for dilution integrity showed a higher concentration analytic sample than the upper limit of the calibration curve, which is within the acceptance limit of $\leq 15 \%$.

\section{Stability}

The stability analysis of auraptene was carried out on samples stored at room temperature $\left(22^{\circ} \mathrm{C}\right)$ for $6 \mathrm{~h}$. From Table 3 , the data indicated that auraptene in plasma showed acceptable stabilities at ambient temperature for $24 \mathrm{~h}$, at $-40^{\circ} \mathrm{C}$ for at least 30 days following three freeze-thaw cycles, and in the autosampler for $48 \mathrm{~h}$. The results were stable within the acceptance limits.

Table 3. Stability of auraptene in rat plasma at various conditions at four QC levels.

\begin{tabular}{|c|c|c|c|c|c|c|c|c|}
\hline \multirow[t]{2}{*}{ Sample condition } & \multicolumn{2}{|c|}{$20 \mathrm{ng} / \mathrm{mL}$} & \multicolumn{2}{|c|}{$50 \mathrm{ng} / \mathrm{mL}$} & \multicolumn{2}{|c|}{$1000 \mathrm{ng} / \mathrm{mL}$} & \multicolumn{2}{|c|}{$1600 \mathrm{ng} / \mathrm{mL}$} \\
\hline & $\begin{array}{c}\text { Measured } \\
(\mathrm{ng} / \mathrm{mL})\end{array}$ & RSD (\%) & $\begin{array}{c}\text { Measured } \\
(\mathrm{ng} / \mathrm{mL})\end{array}$ & RSD (\%) & $\begin{array}{c}\text { Measured } \\
(\mathrm{ng} / \mathrm{mL})\end{array}$ & RSD (\%) & $\begin{array}{c}\text { Measured } \\
(\mathrm{ng} / \mathrm{mL})\end{array}$ & RSD (\%) \\
\hline Freeze-thaw stability & 19.2 & 9.3 & 50.5 & 8.3 & 923 & 4.1 & 1563 & 6.1 \\
\hline Short-term stability & 19.6 & 6.1 & 48.6 & 14.1 & 927 & 0.5 & 1546 & 5.4 \\
\hline Long-term stability & 18.9 & 4.3 & 49.3 & 7.6 & 955 & 2.3 & 1584 & 5.1 \\
\hline Post-preparative stability & 19.1 & 6.6 & 49.6 & 3.9 & 979 & 4.7 & 1520 & 4.3 \\
\hline
\end{tabular}

\section{Application to a pharmacokinetic study}

The validated method in this study was appropriately applied to investigate the pharmacokinetics of auraptene in adult male Wistar rats whose analyte plasma concentrations were determined within $24 \mathrm{~h}$ following intravenous administration $(2 \mathrm{mg} / \mathrm{kg}, \mathrm{N}=6)$ or oral administration $(100 \mathrm{mg} / \mathrm{kg}, \mathrm{N}=6)$. The cardinal pharmacokinetic parameter data dominated for non-compartment modeling with the WinNonlin software standard version 6.1 are summarized in Table 4. The concentration-time curves (mean SD) are seen in Figures 3 and 4, the main pharmacokinetic parameters are given in Table 4.

\section{CONCLUSIONS}

In summary, we have developed a validated LC-MS/MS method that is simple, highly sensitive and specific for the determination of the pharmacokinetics and bioavailability of auraptene in rats, which follows FDA guidelines.

The validated method was approved as suitable for the pharmacokinetic study 


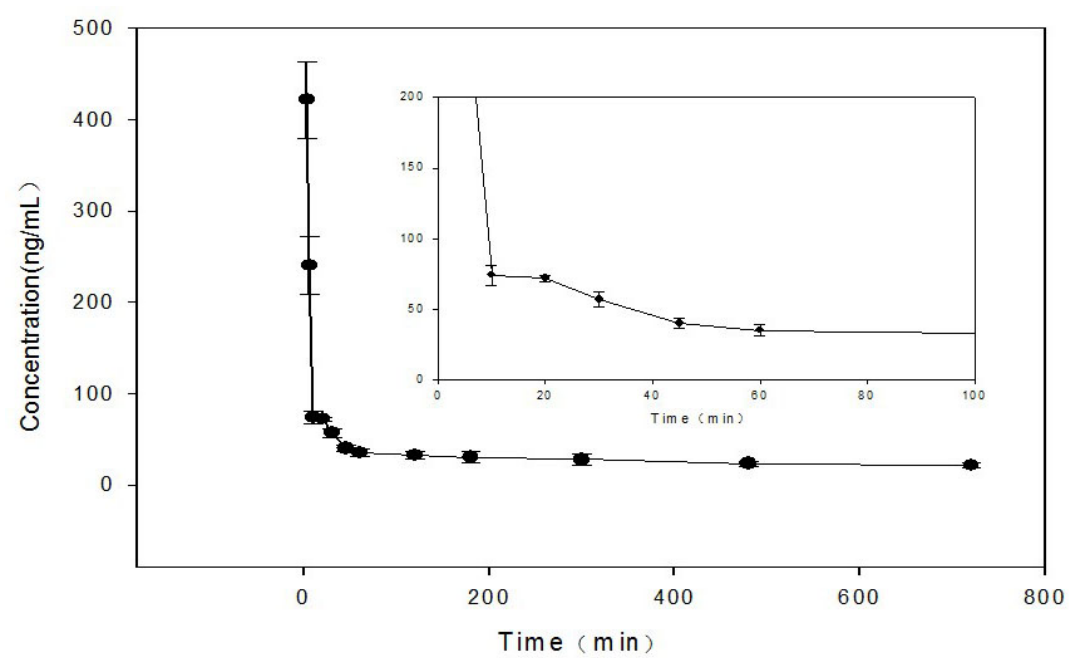

Figure 3. Mean plasma concentration versustime profile of auraptene after intravenous administration of $2 \mathrm{mg} / \mathrm{kg}$ to rats.

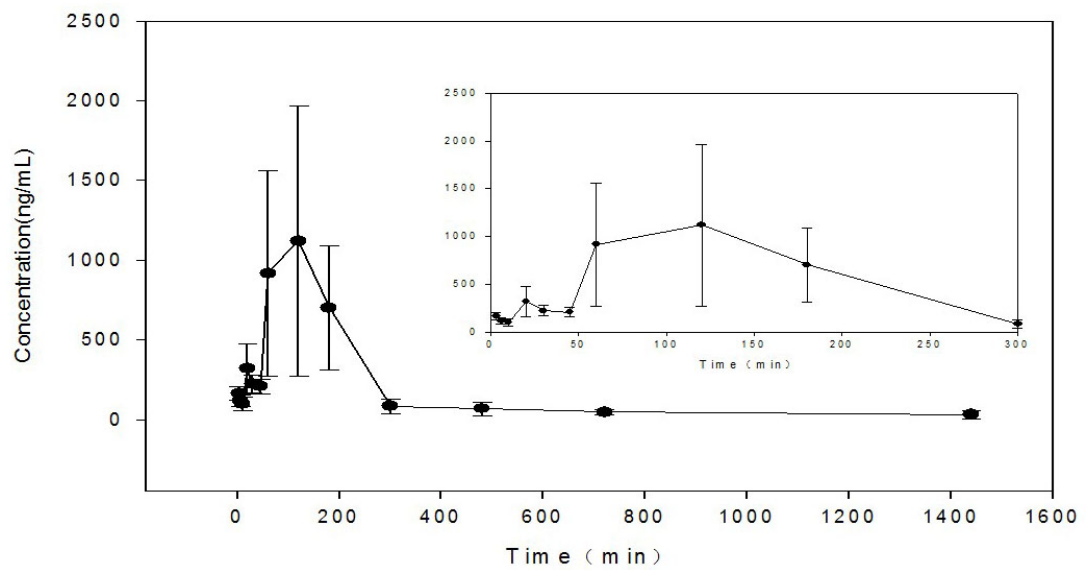

Figure 4. Mean plasma concentration versustime profile of auraptene after intragastric administration of $100 \mathrm{mg} /$ $\mathrm{kg}$ to rats.

Table 4. Mean pharmacokinetic parameters of auraptene after oral and intravenous administrations (means \pm $\mathrm{SD}, \mathrm{N}=6)$.

\begin{tabular}{l|l|c|c}
\hline Parameter & Unit & Oral $(100 \mathrm{mg} / \mathrm{kg})$ & Intravenous $(2 \mathrm{mg} / \mathrm{kg})$ \\
\hline AUClast & $\mathrm{min} \cdot \mathrm{ng} / \mathrm{L}$ & $236,190.1 \pm 5,810.8$ & $24,810.3 \pm 21,778.5$ \\
\hline $\mathrm{t}_{1 / 2}$ & $\mathrm{~min}$ & $775.2 \pm 53.8$ & $913.0 \pm 1,506.8$ \\
\hline $\mathrm{C}_{\max }$ & $\mathrm{ng} / \mathrm{mL}$ & $1,719.5 \pm 384.3$ & $360.2 \pm 440.0$ \\
\hline $\mathrm{T}_{\max }$ & $\mathrm{min}$ & $108.0 \pm 25.3$ & $3.0 \pm 0$ \\
\hline $\mathrm{AUC}(0-\mathrm{t})$ & $\mathrm{ng} \mathrm{min} / \mathrm{mL}$ & $194,732.0 \pm 8,349.1$ & $4,513,216.2 \pm 541,437.5$ \\
\hline $\mathrm{AUC}(0-\infty)$ & $\mathrm{ng} \mathrm{min} / \mathrm{mL}$ & $275,868.0 \pm 9,121.6$ & $5,510,006.8 \pm 652,505.1$ \\
\hline $\mathrm{CL}$ & $\mathrm{mL} / \mathrm{mg} / \mathrm{min}$ & $268.9 \pm 59.3$ & $3.25 \pm 2.3$ \\
\hline $\mathrm{MRT}_{\text {last }}$ & $\mathrm{min}$ & 8.5 & $80.6 \pm 63.9$ \\
\hline $\mathrm{F} \%$ & & &
\end{tabular}


of auraptene in rats, notable for its short chromatographic run time (4 min) and simple, straightforward, and low-cost sample pretreatment procedure.

The calibration curve was linear over the concentration range of $0.5-200 \mathrm{ng} / \mathrm{mL}$, with lower limit of quantification of $0.5 \mathrm{ng} / \mathrm{mL}$. The bioavailability of oral administration of auraptene was merely $8.5 \%$ in rats, which was in concurrence with the results published by the paper as a whole (Li et al., 2011). The possible reason might be extensive metabolism following absorption, and the phenomenon of liver or intestinal breakdown into metabolites. Studies on such questions are ongoing in our laboratory in order to understand the pharmacological effects of auraptene in vivo. The method could not only be the foundation for the further development of auraptene, but also be adapted for pharmacokinetic studies in other biological matrixes.

\section{ACKNOWLEDGMENTS}

Research supported by the National Natural Science Foundation of China (\#30660230, \#81460575, and \#81260612), the National Science and Technology Major Project of Drug Innovation (\#2009ZX09103-350), the Health and Family Planning Commission of Science and Research Fund of Jiangxi Province, the Jiangxi University of Traditional Chinese medicine for providing funds and the necessary facilities to carry out this study.

\section{REFERENCES}

Chen H, Luo L, Yuan J, Luo X, et al. (2012). Protective effect of auraptene on cerebral ischemia-induced vascular dementia in rats. Chin. J. New Drugs 21: 1210-1213.

Chen H, Luo X, Zhang W, Yuan J, et al. (2014). Effects of auraptene on learning and memory deficits induced by scopolamine in rats. Chin. Hosp. Pharm. J. 34: 167-170.

Guo L, Duan L, Dong X, Dou LL, et al. (2014). A simple and sensitive LC-MS/MS method for determination of miltirone in rat plasma and its application to pharmacokinetic studies. J. Chromatogr. B Analyt. Technol. Biomed. Life Sci. 973 : 33-38. http://dx.doi.org/10.1016/j.jchromb.2014.10.008

Kawabata K, Murakami A and Ohigashi H (2006). Citrus auraptene targets translation of MMP-7 (matrilysin) via ERK1/2-dependent and mTOR-independent mechanism. FEBS Lett. 580: 5288-5294. http://dx.doi.org/10.1016/j. febslet.2006.08.072

Li M, Yuan J, Chen H, Liu Y, et al. (2011). Study on excretion behaviors of auraptene via feces and urine after oral administration by rats. J. JiangXi Univ. TCM 23: 70-71.

Tanaka T, Sugiura H, Inaba R, Nishikawa A, et al. (1999). Immunomodulatory action of citrus auraptene on macrophage functions and cytokine production of lymphocytes in female BALB/c mice. Carcinogenesis 20: 1471-1476. http:// dx.doi.org/10.1093/carcin/20.8.1471

Yang W, Chen H, Yu B, Zhang P, et al. (2008). Study on the Active Constituents of Fructus Aurantii. J. Chin. Med. Mat. 12: $1812-1815$.

Ye X, Huang Z, Chen H, Yuan J, et al. (2012). Study on Safety Pharmacology of Auraptene. Trad. Chin. Drug Res. Clin. Pharmacol. 23: 522-526.

Yuan J, Wang F, Li M, Chen H, et al. (2011). Pharmacokinetic study of aurapetene after intravenous injection in rats. Chin. J. Exp. Trad. Med. Formulae 17: 130-133.

Yuan J, Li M, Chen H, Yang W, et al. (2012). An HPLC method for the determination of auraptene in dog plasma: application to pharmacokinetic study. Lat. Am. J. Pharm. 31: 251-256.

Zhang Y, Chen H, Yuan J, Liu Y, et al. (2011). Effect of Auraptene on Learning and Memory of Senescence-accelerated Mice Prone 8 and Its Mechanism. Trad. Chin. Drug Res. Clin. Pharmacol. 22: 498-501. 